\title{
Another option for biliary access in post-bypass patient: intentional disruption of a gastric staple line
}

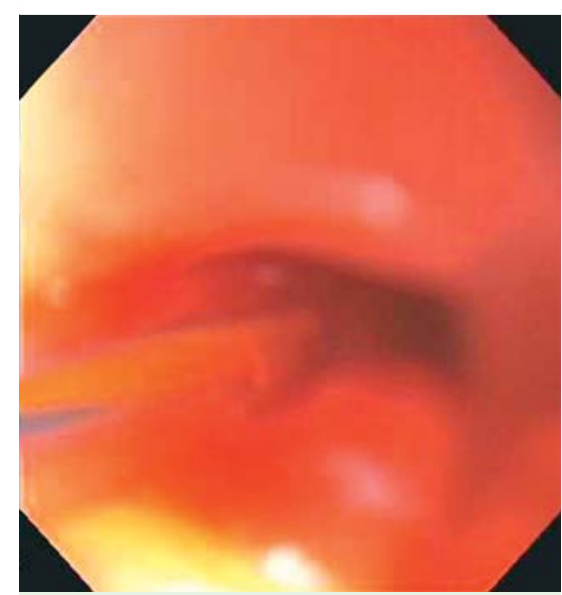

Fig. 1 Fistula tract with wire in a 72-year-old woman who had recently undergone four-vessel cardiac artery bypass, and also had oxygendependent chronic obstructive pulmonary disease, dialysis-dependent end-stage renal disease, and a Roux-en-Y gastric bypass (with cholecystectomy) 30 years ago.

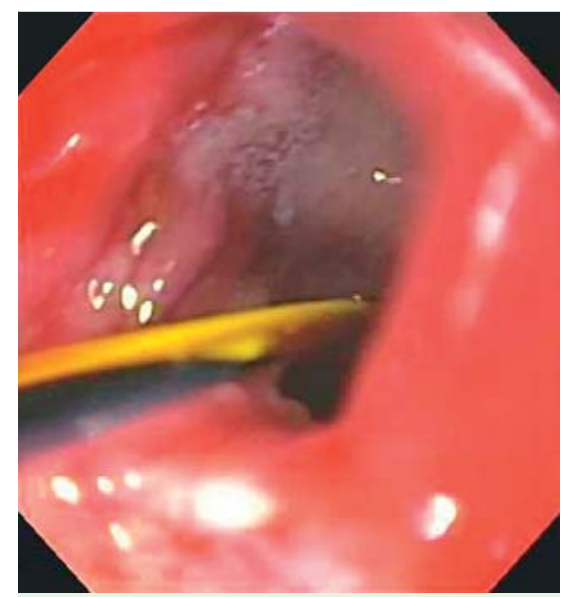

Fig. 3 Dilated fistula tract.

Obese and post-Roux-en-Y gastric bypass (RYGB) patients are at increased risk of cholelithiasis and associated biliary disorders [1-3]. Because of the complicated postsurgical anatomy, endoscopic retrograde cholangiopancreatography (ERCP) may be more difficult, requiring deep enteroscopy or laparoscopic assistance. We report a case of intentional disruption of the gastric remnant-excluded stomach staple line to gain access to the duodenum for treatment of choledocholithiasis.

A 72-year-old woman with past medical history of recent four-vessel cardiac artery

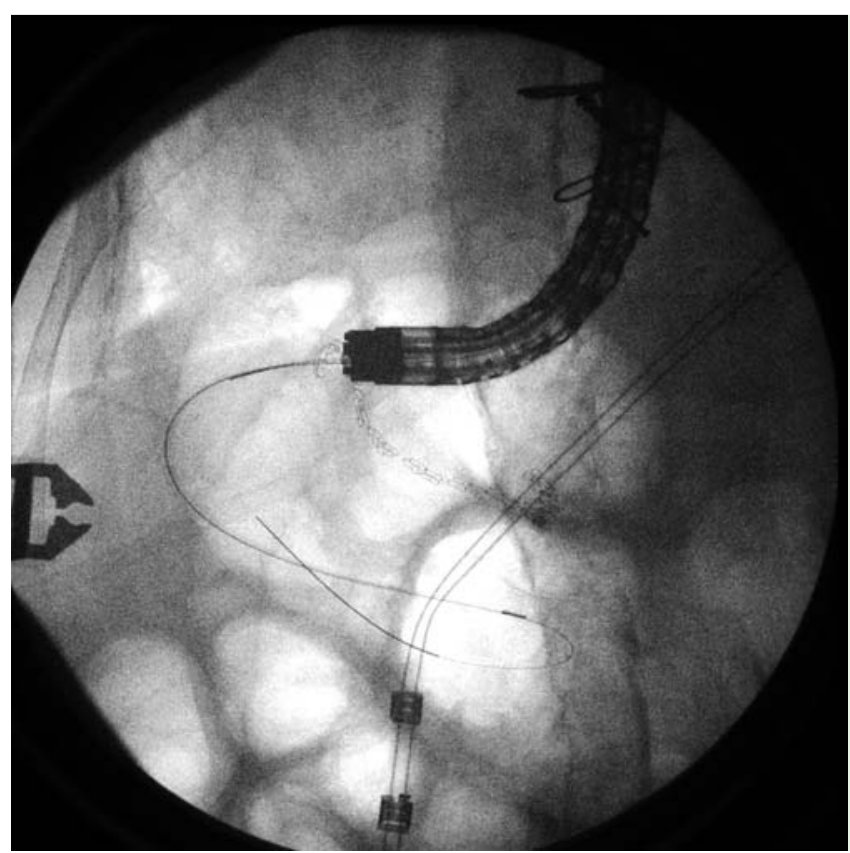

Fig. 2 Fluoroscopic image of cannulatome and wire through staple line fistula into excluded stomach.

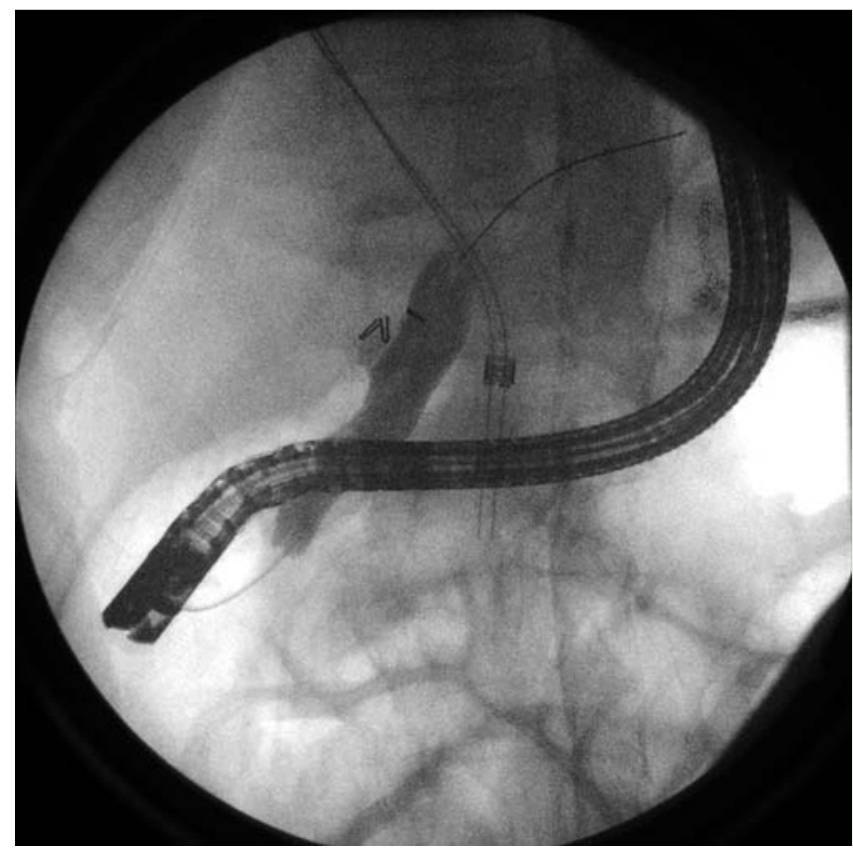

Fig.4 Fluoroscopic image of duodenoscope traversing the disrupted staple line and cholangiogram showing choledocholithiasis.

bypass, oxygen-dependent chronic obstructive pulmonary disease, dialysis-dependent end-stage renal disease, and RYGB with cholecystectomy 30 years ago was admitted at a local hospital with gallstone pancreatitis. She was treated with typical therapy and clinically improved, but on hospital day 3 she was noted to have a persistently elevated total bilirubin of $2.7 \mathrm{mg} / \mathrm{dL}$. Magnetic resonance pancreatography (MRCP) showed a dilated common bile duct ( $12 \mathrm{~mm}$ ) with choledocholithiasis. ERCP was attempted at the local facility, but failed as the jejuno-jejunal anastomosis could not be reached, prompting transfer to our facility.

On repeat ERCP, we accessed to the jejuno-jejunal anastomosis, which was deep- 


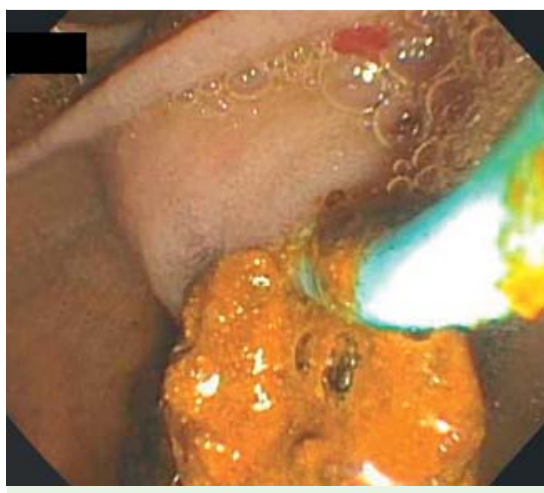

Fig. 5 Stone extraction.

ly intubated to $60 \mathrm{~cm}$, but could not be advanced to the level of the papilla. On removing the colonoscope, scant bile was noted in the gastric pouch. After probing with a sphincterotome, a small fistula tract was noted between the gastric pouch and the excluded stomach along the staple line ( $\bullet$ Fig. 1), verified fluroscopically by wire and contrast injection ( $\bullet$ Fig. 2 ). The fistula was then sequentially dilated to $18 \mathrm{~mm}$ with CRE balloons (Boston Scientific, Cork, Ireland) ( $\bullet$ Fig.3). A duodenoscope was then advanced through the fistula tract and excluded stomach to a normal appearing ampulla. The duct was then deeply cannulated using a wire first technique with subsequent contrast injection revealing a dilated common bile duct to $12 \mathrm{~mm}$ with choledocholithiasis (ه Fig.4). Following a 15-mm sphincterotomy, the duct was swept removing multiple brown pigmented stones ( $\mathbf{F i g . 5}$ ). The fistula tract from the gastric pouch to the excluded stomach was not closed to allow repeat access if necessary. The patient did well and recovered from the episode.

Post-RYBG anatomy can make ERCP difficult, occasionally requiring deep-enteroscopy techniques or laparoscopic assistance to evaluate and treat biliary disorders. Here we have presented a case of intentionally disrupting the staple line excluding the bypassed stomach in a post-RYGB patient to facilitate therapeutic ERCP.

\section{Endoscopy_UCTN_Code_TTT_1AR_2AK}

\section{Competing interests: None}

\section{J. M. Levenick, T. B. Gardner}

Section of Gastroenterology and Hepatology, Dartmouth Hitchcock Medical Center, Lebanon, New Hampshire, USA

\section{References}

1 Shiffman ML, Sugerman HJ, Kellum JM et al. Gallstone formation after rapid weight loss: a prospective study in patients undergoing gastric bypass surgery for treatment of morbid obesity. Am J Gastroenterol 1991; 81: 1000-1005

2 Shiffman ML, Sugerman HJ, Kellum JM et al. Changes in gallbladder bile composition following gallstone formation and weight reduction. Gastroenterology 1992; 103 : 214-221

3 Livingston EH. Procedure incidence and inhospital complication rates of bariatric surgery in the United States. Am J Surg 2004; 188: $105-110$

Bibliography

DOI http://dx.doi.org/

10.1055/s-0032-1326347

Endoscopy 2013; 45: E124-E125

(c) Georg Thieme Verlag KG

Stuttgart · New York

ISSN 0013-726X

\section{Corresponding author}

\section{J. M. Levenick}

Section of Gastroenterology and Hepatology, Dartmouth-Hithcock Medical Center One Medical Center Drive Lebanon, NH 03756 USA

Fax: +603-650-5225

John.m.levenick@hitchcock.org 